\title{
Anaesthetic management for combined emergency caesarean section and craniotomy tumour removal
}

\author{
Dewi Y. Bisri, Caroline Wullur, Tatang Bisri
}

\begin{abstract}
Presentation of primary intracranial tumour during pregnancy is extremely rare. Symptoms of brain tumour include nausea, vomiting, headache and seizures which mimic symptoms of pregnancy-related hyperemesis or eclampsia. In very few cases, craniotomy tumour removal is performed earlier or even simultaneously with foetal delivery.A 40-year-old woman at 32 weeks of gestation in foetal distress presented to the emergency room with decreased level of consciousness Glasgow Coma Scale 6 (E2M2V2). Computed tomographic scan revealed a mass lesion over the left temporoparietal region with midline shift and intratumoural bleeding. In view of high risk of herniation and foetal distress, she underwent emergency caesarean section followed by craniotomy tumour removal. In parturient with brain tumour, combined surgery of tumour removal and caesarean section is decided based on clinical symptoms, type of tumour and foetal viability. Successful anaesthetic management requires a comprehensive knowledge of physiology and pharmacology, individually tailored to control intracranial pressure while ensuring the safety of mother and foetus.
\end{abstract}

Key words: Caesarean section, craniotomy, intracranial tumour, pregnancy

\section{INTRODUCTION}

The incidence of non-obstetric surgery during pregnancy is approximately $0.75 \%-2 \%$. The incidence of occurrence of primary central nervous system (CNS) tumours in females is 6 in 100,000 population, which are less in comparison to that in non-pregnant women of the same age group. Symptoms such as nausea, vomiting, headache, visual disturbances and seizures are often mistaken for pregnancy-related hyperemesis gravidarum during early pregnancy or eclampsia during late pregnancy. Meningioma is the most common primary intracranial

Department of Anaesthesia and Intensive Care, Faculty of Medicine, Padjadjaran University, Hasan Sadikin General Hospital, Bandung, Indonesia

\section{Address for correspondence:}

Dr. Dewi Yulianti Bisri, Department of Anaesthesia and Intensive Care, Faculty of Medicine, Universitas Padjadjaran, Hasan Sadikin General Hospital, Bandung, Indonesia.

E-mail:yuliantibisri@yahoo.com

\begin{tabular}{|l|l|}
\hline \multicolumn{2}{|c|}{ Access this article online } \\
\hline Quick Response Code: & Website: \\
\hline & www.jnaccjournal.org \\
\cline { 2 - 2 } & \\
\hline
\end{tabular}

neoplasm and many of these tumours grow faster during pregnancy as they contain oestrogen and progesterone receptors. Previously asymptomatic and undiagnosed tumours, therefore, may become symptomatic due to the increased growth of tumour or oedema. In addition, increased vascularity or pregnancy-related immunotolerance may also result in tumours becoming symptomatic in pregnant state. In most cases, surgical interventions are delayed until after delivery. However, tumours causing acute neurological deterioration posing a risk of herniation require immediate surgery. The management of combined caesarean section and craniotomy tumour removal is particularly challenging for the anaesthesiologist as it requires a balance of both maternal safety and neonatal consideration. Some neuroanaesthetic techniques or protective interventions may benefit the mother; however, it carries risks for harming the foetus. Rapid sequence induction may elevate maternal blood pressure (BP), hence intracranial

This is an open access article distributed under the terms of the Creative Commons Attribution-NonCommercial-ShareAlike 3.0 License, which allows others to remix, tweak, and build upon the work non-commercially, as long as the author is credited and the new creations are licensed under the identical terms.

For reprints contact: reprints@medknow.com

How to cite this article: Bisri DY, Wullur C, Bisri T. Anaesthetic management for combined emergency caesarean section and craniotomy tumour removal. J Neuroanaesthesiol Crit Care 2017;4:53-6. 
pressure (ICP) while hyperventilation and mannitol may decrease uterine blood flow and induce foetal hypovolaemia. We describe the successful management of a patient who underwent emergency caesarean section which was followed by craniotomy tumour excision.

\section{CASE REPORT}

A 40 -year-old woman $(160 \mathrm{~cm}, 70 \mathrm{~kg})$ at 32 weeks of gestation presented to the emergency department with decreased level of consciousness. Upon arrival, Glasgow Coma Scale (GCS) was 6 (E2M2V2) with BP of $150 / 90 \mathrm{mmHg}$ and heart rate of $120 \mathrm{bpm}$. She had a previous history of caesarean section, and her past medical and neurological history was unremarkable. Differential diagnosis was made for infection (meningitis), haemorrhage (aneurysm, hypertension and pre-eclampsia) and any other causes of increased ICP including brain tumour. All her laboratory parameters were within normal limit. Computed tomography (CT) scan revealed a mass lesion of $6 \mathrm{~cm} \times 7 \mathrm{~cm} \times 10 \mathrm{~cm}$ over the left temporoparietal region, suggestive of a meningioma, with midline shift and intratumoural bleeding [Figure 1]. Obstetric examination revealed a single live foetus of 32-week gestation and was at distress. After a multidisciplinary consultation among the neurosurgeon, obstetrician and anaesthesiologist, it was decided that the patient was under a risk of cerebral herniation in view of the large intracranial mass with midline shift and intratumoural bleeding. Foetal cardiotocography (CTG) and ultrasound revealed foetus in distress. Therefore, an emergent craniotomy as well as caesarean section in one sitting was planned.

The patient was premedicated with ranitidine $50 \mathrm{mg}$ and metoclopramide $10 \mathrm{mg}$ intravenously. A left lateral tilt to prevent aortocaval compression and $15^{\circ}$ reverse

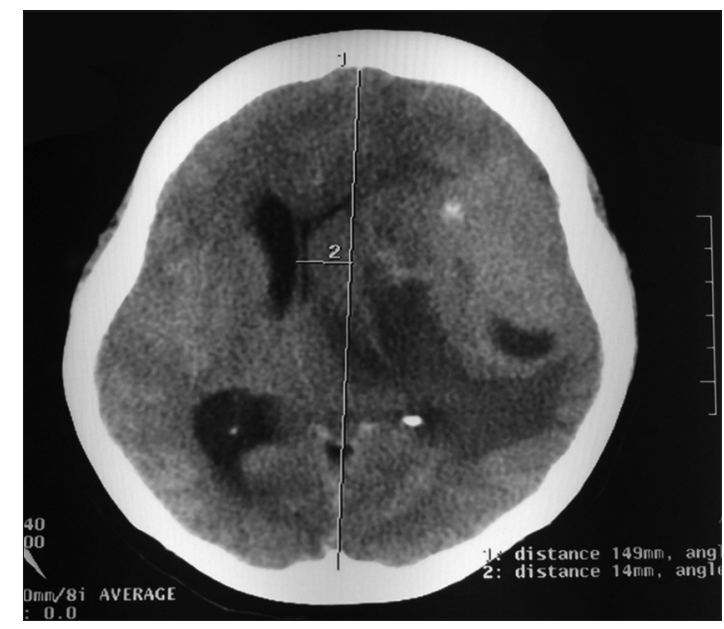

Figure 1: Computed tomography scan revealed a large intracranial mass in the left temporoparietal region with midline shift and intratumoural bleeding
Trendelenburg to decrease ICP were applied to the operating table. One hundred percent oxygen was administered through face mask, and monitoring of non-invasive $\mathrm{BP}$, electrocardiogram and pulse oximetry was done. A 20-gauge intravenous catheter was inserted into the right radial artery for continuous BP monitoring. Prior to induction, BP was $144 / 88 \mathrm{mmHg}$, heart rate was $110 \mathrm{bpm}$ and there was $100 \%$ oxygen saturation. Lidocaine $1.5 \mathrm{mg} / \mathrm{kg}$ was administered. Induction was performed using $2 \mathrm{mcg} / \mathrm{kg}$ fentanyl, $2 \mathrm{mg} / \mathrm{kg}$ propofol and $1.2 \mathrm{mg} / \mathrm{kg}$ rocuronium, while maintaining cricoid pressure. Trachea was intubated using $6.5 \mathrm{~mm}$ inner diameter endotracheal tube without any difficulty. Anaesthesia was maintained using sevoflurane $2 \%$ with $50 \%$ air in $\mathrm{O}_{2}$. Controlled ventilation was maintained at tidal volume of $6 \mathrm{ml} / \mathrm{kg}$ and respiratory rate of 14 breaths $/ \mathrm{min}$. End-tidal $\mathrm{CO}_{2}\left(\mathrm{EtCO}_{2}\right)$ was continually monitored and maintained at $30 \pm 2 \mathrm{mmHg}$. After $8 \mathrm{~min}$ from the time of induction, a healthy girl neonate was delivered, with Apgar scores of 6, 7 and 8 at $1^{\text {st }}, 5^{\text {th }}$ and $10^{\text {th }} \mathrm{min}$, respectively. Additional $50 \mathrm{mcg}$ fentanyl was administered to maintain anaesthetic depth. After placental extraction, slow infusion of $500 \mathrm{cc}$ of $0.9 \%$ $\mathrm{NaCl}$ containing $10 \mathrm{IU}$ oxytocin was started to induce uterine contraction. Intraoperative haemodynamic and respiratory parameters were stable throughout the caesarean section and it was completed within $55 \mathrm{~min}$. The estimated blood loss and urine output at the end of caesarean section was 500 and $100 \mathrm{ml}$, respectively. One unit of packed red blood cell $(220 \mathrm{ml})$ with $700 \mathrm{ml}$ ringerfundin was infused during the caesarean section.

Prior to craniotomy, central venous access was obtained at the right subclavian vein. Craniotomy tumour removal was performed in supine position with $30^{\circ}$ head elevation. Mannitol $0.5 \mathrm{mg} / \mathrm{kg}$ was administered just after scalp incision. Anaesthesia was maintained using sevoflurane $2 \%$ with $50 \%$ air in $\mathrm{O}_{2}$, rocuronium and continuous propofol infusion of $25-50 \mathrm{mcg} / \mathrm{kg} / \mathrm{min}$. Haemodynamic parameters were stable throughout the $5 \mathrm{~h}$ procedure. The central venous pressure was 11-14 $\mathrm{cmH}_{2} \mathrm{O}$. The tumour was resected with estimated blood loss of $800 \mathrm{ml}$ and urine output of $1000 \mathrm{ml}$ throughout the craniotomy. Five hundred millilitres of $4 \%$ gelatin solution, $2000 \mathrm{ml}$ ringerlactate and $210 \mathrm{ml}$ packed red blood cells were administered. The patient was then transferred to the Intensive Care Unit; trachea was extubated on the $4^{\text {th }}$ post-operative day and discharged on $6^{\text {th }}$ post-operative day. Her GCS was $15 / 15$ with no neurological deficits. The neonate was healthy and discharged on day 2.

\section{DISCUSSION}

The management of obstetric patients with brain tumour requires a multidiciplinary approach involving 
the neurosurgeon, obstetrician and anaesthesiologist. The timing of the surgery needs to be individualised according to various factors including neurological status of the mother, possibility of preterm labour, gestational age of the foetus and foetal lung maturity. Many aspects have to be considered, namely the physiological effects of pregnancy on tumour size and effect of labour on maternal cerebral circulation, autoregulation and cerebral perfusion pressure to achieve the optimal outcome. Certain principles are similar while others are conflicting. Anaesthetic technique should be designed to avoid foetal hypoxia, hypercarbia and hypotension. Neuroprotective measures such as hyperventilation or induced hyperosmolarity should be used with caution because hypocarbia, reduced uterine perfusion and foetal hyperosmolarity or dehydration pose serious threats to the foetus. Neuroanaesthetic technique must, therefore, strive to offer optimal care for the mother and minimize risks to the foetus while also ensuring the shortest possible exposure to anaesthetic drugs. Aspiration prophylaxis, pre-oxygenation, haemodynamic stability maintenance and vigilant monitoring are essential. ${ }^{[1-4]}$

Intracranial neoplasms are rare during pregnancy. The tumours tend to grow during pregnancy due to fluid retention, increased blood flow and hormonal changes. Surgery for slow-growing benign tumours may be delayed until foetal delivery based on neurologic status; however, malignant or rapidly growing benign tumours should be excised despite concerns of pregnancy. The general effects of tumours are caused by increased ICP due to tumour mass added to the brain. Hydrocephalus may occur following obstruction of cerebrospinal fluid circulation. Cerebral oedema is a life-threatening complication and may cause displacement/herniation and compression of brain structures resulting in lethal effects including death. ${ }^{[3-6]}$

In this case, the patient presented with decreased level of consciousness and CT scan revealing a large mass with midline shift and intratumoural bleeding. Therefore, from neurosurgical point of view, she required an emergency craniotomy. From the obstetrics point of view, CTG showed that the foetus was in distress and therefore, emergency caesarean section was planned simultaneously.

The management of combined anaesthesia for craniotomy and caesarean section requires a comprehensive knowledge of physiology of mother and foetus and physiology and pharmacology of CNS with the aim for safety of both mother and foetus. With neuroanaesthesia principles, endotracheal intubation must be facilitated carefully to prevent an increase in BP and therefore ICP. However, a rapid sequence induction for caesarean section will induce haemodynamic changes and an increase in ICP. In this case, both lidocaine and fentanyl were utilised to blunt the sympathetic stimulation during tracheal intubation. High dose of rocuronium $(1.2 \mathrm{mg} / \mathrm{kg})$ was used along with Sellick manoeuvre $60 \mathrm{~s}$ prior to intubation. The patient was also premedicated with ranitidine and metoclopramide given the high risk of vomiting and aspiration during pregnancy. ${ }^{[4,7-10]}$

It may be argued that opioid should be withheld due to concerns of neonatal chest wall rigidity and apnoea in the face of augmented stress response and increased ICP in the mother. All opioids administered to the mother prior to delivery may cause neonatal respiratory depression, and therefore skilled personnel in neonatal resuscitation is needed during the procedure. Short-acting opioids, such as fentanyl $(2-5 \mathrm{mcg} / \mathrm{kg})$ or remifentanil $(1 \mathrm{mcg} / \mathrm{kg})$, however, are known to be safe. Lidocaine $(1.5-2 \mathrm{mg} / \mathrm{kg})$ may also be used in conjunction with opioids for blunting response to laryngoscopy. In this case, the neonate was unharmed with a combination of fentanyl and lidocaine during induction of the mother. ${ }^{[2-4]}$

Foetus may be compromised indirectly by maternal hypotension, uterine artery vasoconstriction, maternal hypoxaemia, acid-based changes and any other changes in maternal physiology that reduce uteroplacental perfusion or compromise foetal gas exchanges. To preserve both cerebral and uteroplacental perfusion, maintaining haemodynamic stability is important, which is achieved through appropriate fluid administration and resuscitation, avoidance of aortocaval compression and invasive BP monitoring. ${ }^{[1,5,7,8]}$

Inhalational anaesthetics are safe during caesarean section. Volatile agents as well as $\mathrm{N}_{2} \mathrm{O}$ may elevate ICP due to cerebral vasodilatation but can be reversed by hyperventilation. Avoidance of $\mathrm{N}_{2} \mathrm{O}$ while using high concentration of volatiles to maintain anaesthetic depth may also elevate ICP and inhibit uterine contraction leading to possible post-partum haemorrhage. For maintenance of balanced anaesthesia, volatile agents such as isoflurane or sevoflurane at 1-2 minimum alveolar concentration are effective. Pregnant patients require about $25 \%$ lower dose of most volatile anaesthetics. At these concentrations, only minor increases in uterine blood flow and uterine bleeding are induced while preserving cerebral autoregulation. In this case, use of $\mathrm{N}_{2} \mathrm{O}$ was avoided and anaesthetic depth was maintained using low concentration of volatiles combined with continuous propofol, intermittent rocuronium and opioid. In addition, oxytocin was administered after caesarean section to prevent uterine haemorrhage. Use of ergometrine was also avoided as it may produce hypertension and a further increase in an already elevated ICP in the presence of deranged blood-brain barrier. ${ }^{[6,9-11]}$

Diuresis is often accomplished with osmotic agents or loop diuretics to shrink the brain. This can cause significant negative fluid balance for the foetus which may 
not have clinical significance if mannitol is administered after foetal delivery, as in this case. $30^{\circ}$ head elevation was also done in an attempt to produce a 'slack' brain. Modest maternal hyperventilation to achieve an $\mathrm{EtCO}_{2}$ of $28-30 \mathrm{mmHg}$ to decrease cerebral volume may also be done if more surgical exposure is required..$^{[11-13]}$

\section{CONCLUSION}

The time of delivery and decision to combine caesarean section with craniotomy is normally based on the location and pathology of the intracranial tumour, clinical symptoms, gestational age and foetal viability. In such scenario, comprehensive understanding of maternal and foetal physiology along with a multidisciplinary approach involving neurosurgeon, obstetrician and anaesthesiologist is required to achieve a better perioperative outcome.

\section{Financial support and sponsorship}

Nil.

\section{Conflicts of interest}

There are no conflicts of interest.

\section{REFERENCES}

1. Hool A. Anesthesia in pregnancy for non-obstetric surgery. Anaesthesia Tutorial of the Week 185; 2010. p. 1-9.
2. Fast A, Shapiro D, Ducommun EJ, Friedmann LW, Bouklas T, Floman Y. Low-back pain in pregnancy. Spine (Phila Pa 1976) 1987;12:368-71.

3. $\mathrm{Ng} \mathrm{J}$, Kitchen $\mathrm{N}$. Neurosurgery and pregnancy. J Neurol Neurosurg Psychiatry 2008;79:745-52.

4. Khurana T, Taneja B, Saxena KN. Anesthetic management of a parturient with glioma brain for cesarean section immediately followed by craniotomy. J Anaesthesiol Clin Pharmacol 2014;30:397-9.

5. Reitman E, Flood $P$ Anaesthetic considerations for non-obstetric surgery during pregnancy. $\mathrm{Br} \mathrm{J}$ Anaesth 2011;107 Suppl 1:i72-8.

6. Morgan GEJr., Mikhail MS, Murray MJ. Clinical Anesthesiology. $4^{\text {th }}$ ed. New York: McGraw-Hill Companies; 2006. p. 216-7.

7. Wang LP, Paech MJ. Neuroanesthesia for the pregnant woman. Anesth Analg 2008;107:193-200.

8. Sahu S, Lata I, Gupta D. Management of pregnant female with meningioma for craniotomy. J Neurosci Rural Pract 2010;1:35-7.

9. Chung JH, Rho JH, Jung TH, Cha SC, Jung HK, Lee C, et al. Anesthetic management of a parturient for combined cesarean section and surgical removal of pituitary tumor - A case report-. Korean J Anesthesiol 2012;62:579-83.

10. Van De Velde M, De Buck F. Anesthesia for non-obstetric surgery in the pregnant patient. Minerva Anestesiol 2007;73:235-40.

11. Qaiser R, Black P. Neurosurgery in pregnancy. Semin Neurol 2007;27:476-81.

12. Kuczkowski KM. The safety of anaesthetics in pregnant women. Expert Opin Drug Saf 2006;5:251-64.

13. Wlody DJ, Weems L. Anesthesia for neurosurgery in the pregnant patient. In: Cotttrell and Young's Neuroanesthesia. $5^{\text {th }}$ ed., Ch. 23. Philadelphia: Elsevier; 2010. p. 416-24. 